\title{
Some Non-Specific Serological Tests in Leprosy
}

Alan McKenzie.

(Continued from Vol. IV, No. 2.)

The Serum Formalin Reaction among Cases of LEPROSY.

The Serum Formalin Reaction has been investigated among a series of 130 cases of leprosy during a period of two years. All these patients have been under continuous treatment and the variations of the reaction have been correlated with changes in their conditions.

Table 1 gives an analysis of the reaction among each of the three classifications of the disease on the first occasion on which it was performed in each case.

TABLE 1.

\begin{tabular}{|c|c|c|c|c|c|c|c|c|c|c|c|}
\hline Serum $V$ & $\begin{array}{l}\text { Value of } \\
\text { Formalin }\end{array}$ & Reaction. & & 0 & 1 & 2 & 3 & 4 & 5 & 6 & Totals. \\
\hline \multicolumn{4}{|c|}{ Number of patients examined } & 15 & 19 & 21 & 18 & 17 & 23 & 17 & 130 \\
\hline Group I & .. & . & .. & 1 & 1 & 2 & 7 & 8 & 8 & 14 & 41 \\
\hline Group II & .. & .. & .. & 11 & 17 & 16 & 6 & 8 & 9 & 3 & 70 \\
\hline Group II & .. & .. & $\ldots$ & 3 & 1 & 3 & 5 & 1 & 6 & 0 & 19 \\
\hline
\end{tabular}

The majority of these cases had been under treatment for some considerable time prior to the performance of the reaction, and the table can show nothing more than that there are a greater proportion of high Serum Formalin Reactions among those patients who belong to Group I, and perhaps that the greater the number of bacilli in the body the higher one may expect the S.F.R. to be.

Only 36 patients had their S.F.R. examined prior to the commencement of treatment and the analysis is given in Table 2. All these cases were very early ones, generally showing only slight evidence of the disease.

TABLE 2.

\begin{tabular}{|c|c|c|c|c|c|c|c|c|c|c|c|}
\hline $\begin{array}{ll} & V \\
\text { Serum } & F\end{array}$ & $\begin{array}{l}\text { Value of } \\
\text { Formalin }\end{array}$ & Reaction. & & 0 & 1 & 2 & 3 & 4 & 5 & 6 & Totals. \\
\hline \multicolumn{4}{|c|}{ Number of patients examined } & 1 & 5 & 6 & 6 & 4 & 9 & 5 & 36 \\
\hline Group I & .. & . & $\cdots$ & & & & 2 & & 4 & 3 & 9 \\
\hline Group II & $\ldots$ & $\ldots$ & $\cdots$ & 1 & 5 & 6 & 3 & 3 & 3 & 2 & 23 \\
\hline Group. III & $\ldots$ & $\ldots$ & $\ldots$ & & & & 1 & 1 & 2 & & 4 \\
\hline
\end{tabular}


The higher figures are again seen among Group I cases while the reaction of the Group II tends to be low. As a diagnostic aid, therefore, the Serum Formalin Reaction is of no use at all since the diagnosis of Group I rarely presents any difficulty, and there is no guarantee of a high reaction in a Group II case.

Turning to the changes of this reaction during treatment and examining the results in each class separately, we have the results shown in Tables 3,4 and 5. Again the S.F.R. recorded is the value on the first occasion it was performed on that particular case, and the behaviour of the reactions is given in the final three columns.

Table 3 shows the variation of the reaction among the Group I cases where the progress of the disease can be assessed with more accuracy than in the other Groups. Progress is recorded as Much Improved (M.I.), Improved(I.), No Change (I.S.Q.) and Worse (W.).

TABLE 3.

All observations have been recorded over a minimum of nine months.

\begin{tabular}{|c|c|c|c|c|c|c|}
\hline \multirow{2}{*}{\multicolumn{3}{|c|}{$\begin{array}{l}\text { Results of } \\
\text { Treatment. }\end{array}$}} & \multirow{3}{*}{$\begin{array}{c}\text { Number } \\
\text { of Cases. } \\
13\end{array}$} & \multicolumn{3}{|c|}{ Behaviour of S.F. Reaction. } \\
\hline & & & & \multirow{2}{*}{$\begin{array}{c}\text { Rose. } \\
0\end{array}$} & \multirow{2}{*}{$\frac{\text { Stationary. }}{1}$} & \multirow{2}{*}{$\begin{array}{r}\text { Fell } \\
12\end{array}$} \\
\hline M.I. & $\cdots$ & . & & & & \\
\hline I. & $\cdots$ & . & 5 & 1 & 3 & 1 \\
\hline I.S.Q. & $\cdots$ & . & 5 & 1 & 3 & 1 \\
\hline W. & $\ldots$ & .. & 13 & 9 & $4^{*}$ & 0 \\
\hline
\end{tabular}

* The S.F.R. of all these four cases was 6 at the commencement of the period under review.

I think, without further amplification, this Table clearly shows that the S.F. Reaction tends to rise or fall with the varying fortunes of the disease; falling as the leprotic condition improves (out of 13 recorded as Much Improved the reaction was seen to fall in 12), and rising as the disease progresses (among 13 who became worse in spite of treatment, the S.F. values rose in all but 4 , who all showed the maximum value from the first).

Certain of the more striking cases can well be taken as examples.

P.122.-A very early Ib case, whose sole lesion was a small patch of

thickened skin near the left nostril. B. leprae were found in this patch $22 / 12 / 30$ - Had frequent slight reactions, with mild temperature, face, $\begin{array}{llllll}\text { legs and hands became swollen } & \ldots & \ldots & \ldots & \ldots & \text { S.F.R.4 }\end{array}$ $\begin{array}{lllllll}2 / 3 / 31 & \text { Swelling of face diminished } & \ldots & \ldots & \ldots & \ldots & \text { S.F.R. } \\ & \ldots & \ldots & \ldots & \ldots & \text { S.F.R.3 }\end{array}$ $\begin{array}{lllllll}11 / 5 / 31 \text {-Original patch disappeared } & \ldots & \ldots & \ldots & \ldots & \ldots & \text { S.F.R.2 }\end{array}$ 
P.121.-Originally a IIa case on admission, with patches all over the body and anaesthesia in some of them.

$16 / 6 / 30-\ldots \quad \ldots \quad \ldots \quad \ldots \quad \ldots$

S.F.R.4

$29 / 9 / 30$ - Fine nodules appeared over the forehead in which B. leprae $\begin{array}{lllllllll}\text { were found } & \ldots & \ldots & \ldots & \ldots & \ldots & \ldots & \ldots & \text { S.F.R.6 }\end{array}$ 3/11/30-Reaction finished, but B. leprae still found in forehead S.F.R.5

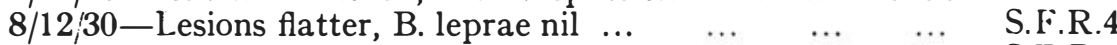

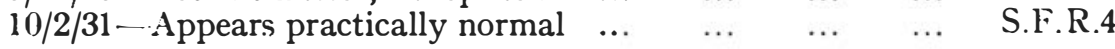

P.36. A Ib case, with early nodules in face and ears.

$1 / 4 / 30-$

Condition appeared to improve unt il

$2 / 12 / 30$ - Lesions began to swell and there was a rise of temperature

S.F.R.5

10/2/31-Lesions less, but painless enlargement of testicles appeared

S.F.R.6

P.11 Ib.-A case of long history who had been treated without reaction or change in the lesions for two years. General condition appeared good but there were many nodules all over the face and trunk, appearing and disappearing without any febrile or other constitutional disturbance. Before reaction S.F.R. was 6.

17/3/30-Severe reaction commenced. All nodules swelled up and ulcerated. Grave constitutional disturbance. Great loss of weight and high temperature. This reaction lasted until

10/6/30 - When ulcers started to heal and there was no signs of raised nodules left.

1/7/30 - Patient started to put on weight again $\quad \ldots \quad \ldots \quad$ S.F.R.5 $24 / 9 / 30$ - No further ulceration or nodule formation $\ldots . \quad \ldots \quad$ S.F.R.4 10/2/31 — Patient regained normal weight, lesions better $\quad \ldots \quad$ S.F.R.3

Tables 4 and 5 show the changes in the Serum Formalin Reaction among patients of Groups II and III respectively.

tABLE 4.-Group II Cases.

\begin{tabular}{|lcr|c|c|c|c|}
\hline \multicolumn{2}{|c|}{$\begin{array}{c}\text { Results of } \\
\text { Treatment. }\end{array}$} & $\begin{array}{c}\text { Number } \\
\text { of Cases. }\end{array}$ & \multicolumn{3}{c|}{ Behaviour of the S.F. Reaction. } \\
\hline M.I. &. & $\ldots$ & 23 & 1 & Stationary. & Fell. \\
\hline I. &. &. & 13 & 1 & $10^{*}$ & 12 \\
\hline I.S.Q. &. &. & 13 & 5 & 10 & 2 \\
\hline W. &.. &.. & 5 & 5 & 8 & 0 \\
\hline
\end{tabular}

* Four of these ten cases gave a S.F. value of 0 at the commencement of the period in question.

TABLE 5.-Group III CASES.

\begin{tabular}{|lcr|c|c|c|c|}
\hline \multicolumn{2}{|c|}{$\begin{array}{c}\text { Results of } \\
\text { Treatment. }\end{array}$} & $\begin{array}{c}\text { Number } \\
\text { of Cases. }\end{array}$ & \multicolumn{3}{c|}{ Behaviour of the S.F. Reaction. } \\
\hline M.I. &.. &. & 6 & - & 1 & 5 \\
\hline I. &.. &. & - & - & - & - \\
\hline I.S.Q. &.. &.. & 10 & 5 & 2 & 3 \\
\hline IV. &.. &.. & 2 & 1 & 1 & - \\
\hline
\end{tabular}


In both these groups it is more difficult to estimate progress than in the first group, and consequently the correlation of a rising S.F. with progression of the disease is less striking.

It is demonstrable, however, that the same tendency exists among these cases in whom few or no bacilli can be found as among that group in which bacilli is found in large numbers and with ease.

\section{Illustrative Cases.}

P.111, IIa. Admitted 20/3/30-Pale patches all over body and legs; Anaesthesia at the centre of most of these patches

29/9/30 - A febrile swelling of many lesions ... S.F.5 $11 / 5 / 31$ - Lesions now practically invisible, but anaesthesia as before ...

S.F.2

P.114, III Admitted 6/6/30 - A few skin patches, but nerve type anaesthesia over both forearms, and both ulnar nerves enlarged.

$18 / 6 / 30$ 15/9/30 - Anaesthesia diminished in extent; patches darker

S.F.3

S.F.2

11/5/31 - Patches almost invisible. Area of anaesthesia less $\begin{array}{lllllll}\text { on hands ... } & \ldots & \ldots & \ldots & \ldots & \ldots & \text { S.F.1 }\end{array}$

The administration of iodides in leprosy produces changes in the Serum Formalin Reaction comparable with that observed in the Sedimentation Index. The following case recounted in detail demonstrates this well.

P.14. An old leonine case, was considered cured. No bacilli had been found after many examinations, either at the sites of the old lesions or by gland puncture. He was admitted to the general hospital, and potassium iodide administered. When the dose of iodide had reached $360 \mathrm{gr}$. per day he began to show a rise of temperature up to about 102 deg. F., and a few bacilli were found in a nasal scraping. Treatment was recommenced with hydnocreol, and after nine months he was again submitted to the iodide test, this time without any effect following a dosage of $480 \mathrm{gr}$. of potassium iodide per day. His S.F.R. was now 0 . $(18 / 6 / 30)$. Treatment was discontinued and he was considered cured.

9/3/31 he appeared again at the clinic and showed some small pale raised patches on the chest and abdomen, which were not anaesthetic and in which no bacilli could be found, S.F.R.2.

He was admitted to hospital and iodides given with the 
Comparison of Sedimentation Index and Serum Formalin Reaction

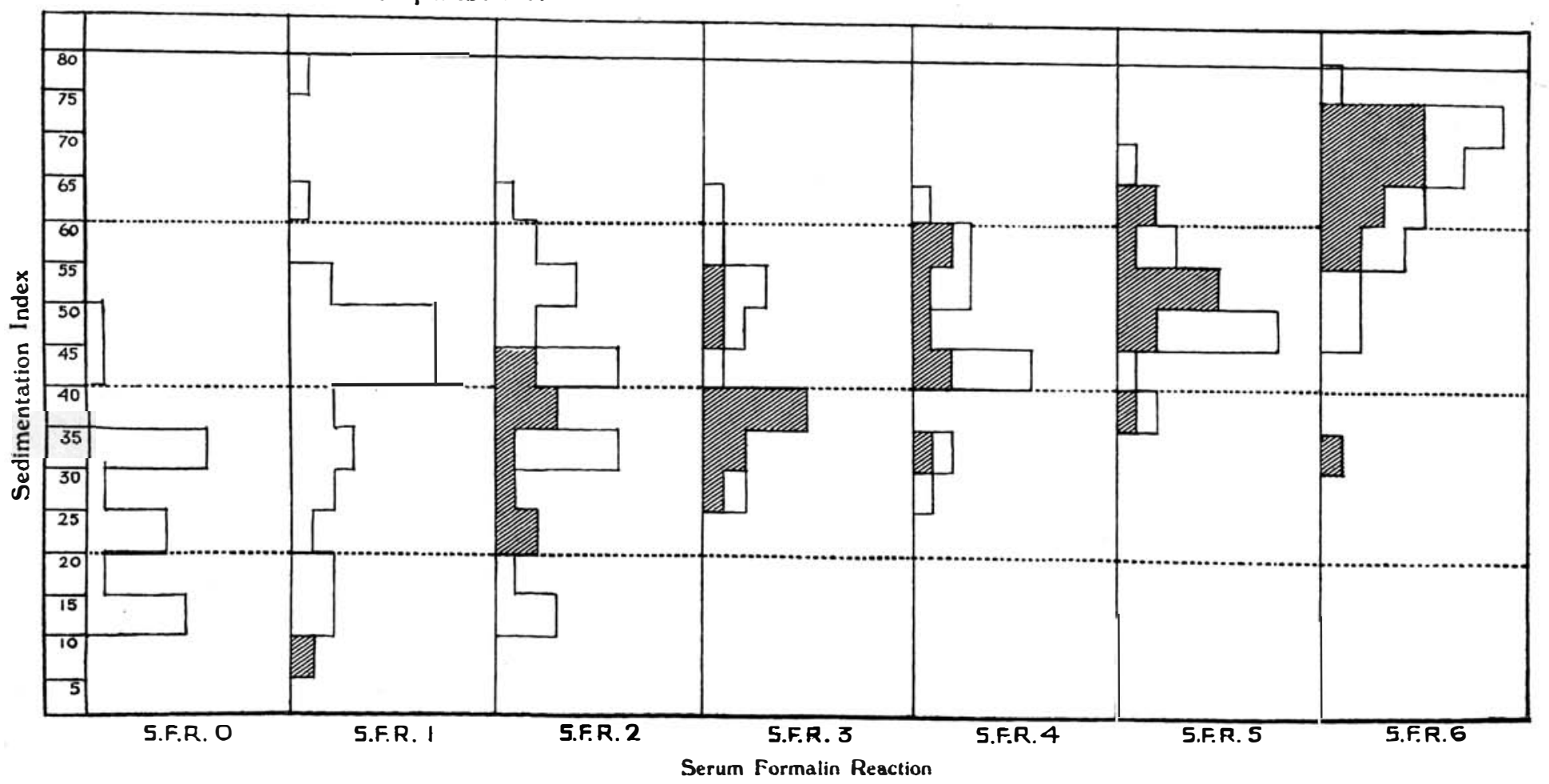


following result.

The Sedimentation Index at each examination is also given for comparison.

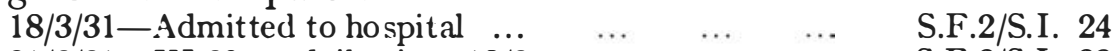

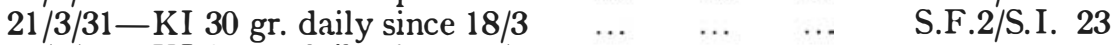

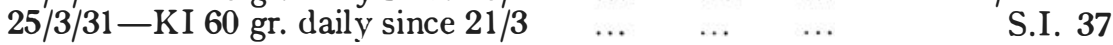

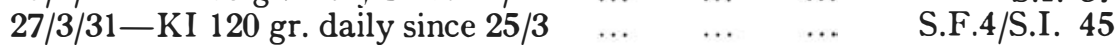

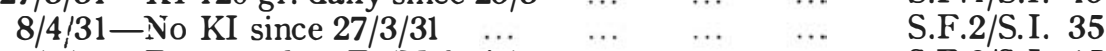

10/4/31-T. 100.8 deg. F. (Malaria) $\quad \ldots \quad \ldots \quad \ldots \quad$ S.F.2/S.I. 45

It was considered that a relapse had occurred and he has now recommenced treatment for a further period.

Other cases in which the iodide test was used to determine whether the patient was cured, and in which the administration of iodides produced no temperature or rise in the Sedimentation Index, also caused no change in the Serum Formalin Reaction.

Leprosy, therefore, especially when a large number of bacilli are found in the body, affects the S.F. reaction in the same way as the granulomatous group of diseases referred to above, and the reaction rises or falls as the disease progresses or improves.

When considering the behaviour of the S.F. Reaction among non-leprous patients it was suggested that the reaction was only slightly, if at all, influenced by the majority of the less chronic diseases ; it should, therefore, be expected that a comparison of the S.F. Reaction with the Sedimentation Index would yield valuable information as to whether an increase in the Sedimentation Index or an observable state of ill-health was due to the primary disease itself or to some other infection. This has proved to be true and is the most valuable application of the Serum Formalin Reaction.

The accompanying graph shows all the simultaneous readings of the Serum Formalin Reaction and the Sedimentation Index that have been performed up-to-date.

The Sedimentation Index is plotted vertically and the Serum Formalin Reaction horizontally.

The shaded portion of the curve represents the cases belonging to Group I and the clear portions those of Groups II and III which are combined, since the number of cases of Group III is relatively small.

It is seen that though there is a general tendency for the results to fall into a definite curve and a high Serum Formalin Reaction to be associated with a high Sedimentation Index, the limits of the corresponding Sedimentation Index associated with the lower values of the Serum Formalin Reaction 
tend to broaden out and a high Sedimentation Index is frequently associated with a low Serum Formalin Reaction.

This occurs mainly in the Group II and Group III cases, the symmetry of the curve being well maintained in Group I.

The study of the exceptions to the general drift of the curve forms the greatest proof of its utility.

The history of some of the most prominent exceptions to the general draft of the graph are as follows :-

109. IIa. Had an anaesthetic depigmented patch on the forearm which is now pigmented normally, though anaesthesia is still present at the centre of what was the patch. Leprosy is considered cured but the patient has suffered from a recurrent bronchitis for the last nine months. S.F.R.O., S.I.49.

136. IIa. Depigmented anaesthetic patches on chest and hands which were pigmenting normally.

20/4/31. Has just had a severe attack of bronchopneumonia in which jaundice appeared, temp. now normal. S.F.1., S.I.63.

29/5/31. Better, but the cough is still troublesome, jaundice has vanished. S.F. 6., S.I. 56.

$15 / 6 / 31$. The cough is better but the general condition of the patient is very poor, he is nearly half his previous weight. S.F. 6, S.I. 44.

(It is suggested that the jaundice can be explained in terms of leprotic invasion of the liver; an increase of the S.F. Reaction not having been found in four cases of nonleprotic jaundice; thus accounting for the sudden increase in the S.F. Reaction.)

80. A II a case, with involvement of the ulnar nerves. Depigmented patch on the back which pigmented normally with disappearance of the anaesthesia. Trophic ulcers continued to appear at infrequent intervals, while the anaesthesia in the distribution of the ulnar nerve remained unchanged.

$22 / 4 / 31$, there were no ulcers on the hands. There was a high temperature which lasted for three days and malaria was diagnosed clinically. S.F.1, S.I.76. S.I.60.

11/5/31. Patient has had no further fever. S.F.3,

$29 / 5 / 31$. Severe trophic ulcers appearing on the left hand. There has been no sign of change in the IIa lesions, and anaesthesia and the old patches have gone. S.F.2, S.I.63.

Of the II and III cases, with a Serum Formalin Reaction of 1 or 2 , the incidence of ulcers is interesting. Taking 40 
to 45 as the normal upper limit of the Sedimentation Index :

Of 9 cases having a S.F. Reaction of 1 and a S.I. greater than 45,6 , or $66.6 \%$, have ulcers.

Of 19 cases with the same S.F. Reaction whose S.I. is less than 45 , only 2 , or $10.5 \%$, have ulcers.

Of 8 cases having a S.F. Reaction of 2 and an S.I. of over 45 , ulcers are found among 5 , or $62.5 \%$, while among 13 , where the S.I. is less than 45 , only 1 case, or $7.7 \%$, had a trophic ulcer.

Turning to the other end of the graph we have the following case :-

95. This case was admitted with IIa lesions. Five months after admission he began to show thickening of the subcutaneous tissues of the face, in which large numbers of bacilli were found. These gradually increased in size until he became a typical leonine case. During the whole period while these changes took place there was no rise of temperature, and the advance of the disease did not appear to affect his general fitness. The S.F.R. rose from 4 at the beginning of the change, to 6 , which is its present value. The S.I. remained throughout around the level of 35 .

\section{Discussion.}

It has been observed, mainly during the treatment of Group I cases, that an exacerbation of the disease, shown either by an increase in size or extent of the existing lesions, or by the appearance of new ones, was signalled by an increase in the value of the S.F. Reaction. This increase has on occasions been found to precede by some considerable time the observation of clinical change. In other cases the rise in the S.F. Reaction and the clinical changes went hand in hand. Although observations are few it appears that when a sudden "lepra reaction" is about to occur with the concomitant phenomena of general malaise and the abrupt production of a crop of new lesions, the warning conveyed by the increase in the S.F.R. is early. When, however, the lesions slowly extend without the sudden production of new ones and the "reaction" phenomenon is absent to a greater extent, the S.F.R. tends to lag and the clinical and serum changes appear concurrently.

With the termination of the "reaction" the S.F.R. usually falls as the newly-formed lesions subside, lagging behind the clinical improvement. Only in one case has the improvement in the appearance of the lesions after a reaction been unaccompanied by a fall in the S.F. Reaction. In this case, although nodular lesions on the face markedly 
decreased, the general condition of the patient remained very poor and a progressive loss of weight was recorded, while subsequent to the termination of the reaction the S.F. Reaction remained high and the S.I. rose considerably.

In only one case has an apparent increase of lesions been unaccompanied by an increase in the S.F. Reaction. This was an early Ia case in whom bacilli, though always present, have throughout been very scanty. His S.F. Reaction has remained constantly for the last eighteen months at 2; although about nine months ago he went through a period when he complained of general malaise and there was an accompanying swelling of the facial tissues which gave the skin a stretched and shiny appearance. No new lesions appeared and although pre-existing nodules in the ears increased in size, there was no fever. The face regained its normal aspect and throughout this period the general health remained good.

Apart from these exceptions the S.F.R. has invariably risen immediately before or with the commencement of a reaction. With the subsidence of symptoms, if the newlyformed lesions abated, the S.F.R. commenced to fall a week or two after the start of the clinical improvement.

During the treatment of patients whose course was not interrupted by the appearance of the dramatic reactive phenomenon, the clinical improvement was generally associated with a fall in the value of the S.F.R. and an advance of the disease by a rise.

In only two cases has an amelioration of the visible signs of leprosy occurred with a rise in the S.F. value, while an advance of the disease has never been accompanied by a fall in this reaction. In only one case (belonging to Group III, and consequently presenting extreme difficulty in the proper apportioning of the clinical picture to the results of leprosy per se) has a reaction remained stationary (unless it was previously of the maximum value) while the clinical picture presented an advance of the disease.

From these data and from the fact that the S.F.R. is more generally high in Group I, it is argued that the S.F.R. is a measure of the severity of the disease and that changes in the course of the disease are accompanied by corresponding changes in the reaction.

The simultaneous study of the S.F.R. and S.I. shows that especially among Group 1 cases, and among Groups II and III, where the S.F.R. is 3 or over, definite values of one reaction tend to be associated with definite values of the other. 
This association is less marked in Groups II and III cases, where the S.F. Reaction is 2 or under.

From the examination of these two reactions among non-leprous patients, it was concluded that only a small number of diseases seriously affected the S.F.R., while the S.I. was influenced not only by an illness, but also by states of debility, not amounting to actual disease. It may be possible, therefore, to explain the divergencies among the lower values of the S.F.R. in terms of added infections. This hypothesis has been investigated, and it has been shown to hold for several cases where a secondary disease could definitely be demonstrated. Where no secondary disease was found the influence of sepsis as recorded in the greater frequency of ulcers among those with a high S.I., but a low S.F.R., was demonstrated.

One case showed an increasing S.F.R. with a stationary S.I., and clinically, although the leprous lesions appeared to be advancing, there was no debility, and the fitness of the patient was maintained.

It has been noticed that after an acute febrile disease the S.I. having risen during the attack, and the S.F.R. remained low, the S.F.R. might rise subsequent to the recovery of the patient. It may be that this is due to the lowering of resistance by the acute infection, permitting a slight exacerbation of the leprosy, or it may simply be due to the effect of the secondary disease upon the reaction. In the case of 136 quoted above, where the S.F.R. during an attack of pneumonia was 1 , and a month later had risen to 6 , where it has since remained, it is suggested that the jaundice which accompanied the later stages of the attack can be explained by an infection of the liver by the leprosy bacillus. In other cases, where an attack of malaria was followed by the appearance of severe trophic ulcers in the hands and a rise in the S.F.R., it appears probable that the disease has advanced, though there is a possibility of there having been no change in the leprotic condition; the increase in the S.F.R. being related to the antecedent malaria only, and the ulcers due to coincidence or merely lowered resistance, cannot be disproved.

In a selected number of cases the two reactions have been performed at frequent intervals and it was noticeable that the S.I. was very unstable as compared with the S.F.R. Large variations have occurred in the S.I. which could not be reconciled with any clinical change, while a steady value of the S.F.R. was maintained. 
In the discussion of these reactions among normal subjects it was shown with what delicacy the S.I. could express not only observable sickness, but also the finer shades of debility. It is arguable, therefore, that among persons suffering from a disease such as leprosy, whose wellbeing is in a state of more delicate balance than would be the case of a normal person, quite trivial and unnoticeable factors might have an exaggerated influence upon this test. The patients who are the subject of this enquiry are not living an institutional life, but can more properly be described as out-patients; and as such they are exposed to many undiscoverable influences and their minor chi...nges of health are difficult to assess.

For some time past the conception of the S.F.R. as being largely a measure of the leprotic portion of a patient's disease and the S.I. as being influenced, firstly by the leprosy, but also by any other concurrent illness and by minor states of ill-health, has been used in the interpretation of results. It has generally been very successful and a distinct aid to treatment.

It has also been shown that the administration of potassium iodide to a patient produces similar rises in both reactions, and that when the administration of the drug is stopped, both tend to fall.

The possibility of the Serum Formalin test having some prognostic value has been examined, and the following Table shows the results obtained. The cases considered are those who have been under treatment for twenty months or more, and in whom the reaction was examined at least a year ago. The reaction given is the finding on the first occasion it was performed in that particular case.

TABLE 6.

\begin{tabular}{|c|c|c|c|c|c|c|c|c|c|c|c|}
\hline \multirow{2}{*}{\multicolumn{3}{|c|}{$\begin{array}{l}\text { Results of } \\
\text { Treatment. }\end{array}$}} & \multirow{3}{*}{$\begin{array}{c}\text { Number } \\
\text { of Cases. } \\
17\end{array}$} & \multicolumn{8}{|c|}{ Value of S.F.R. at beginning of period. } \\
\hline & & & & $\mathbf{0}$ & 1 & 2 & 3 & 4 & 5 & 6 & \\
\hline M.I. & .. & $\cdots$ & & 3 & 5 & 2 & 3 & 2 & 2 & - & \\
\hline I. & $\cdots$ & $\cdots$ & 16 & 1 & 4 & 4 & 2 & 1 & 2 & 2 & \\
\hline I.S.Q. & .. & .. & 7 & - & 3 & 1 & - & 2 & 1 & - & \\
\hline W. & - & .. & 13 & 2 & - & - & 3 & 1 & 1 & 6 & \\
\hline Totals & .. & .. & 53 & 6 & 12 & 7 & 8 & 6 & 6 & 8 & \\
\hline
\end{tabular}

On comparing more particularly the " much improved " with the "worse" column, there appears a certain coincidence between a high initial S.F.R. and a poor prognosis and a low S.F.R. and a more hopeful outlook, but it must 
be pointed out that a number of these cases had received treatment before the S.F. test was first performed, and it is, of course, impossible to say what influence this may have had. One or two cases appeared practically cured before the initial observation was made.

Regarding the S.F.R. as a measure of the gravity of the disease, the results can be explained by the obvious corollary that a smaller proportion of severe cases will show improvement in a given time than of a like number of mild ones. Among early cases where the reaction is in general low, we should expect a greater average improvement than with later and more involved cases. The Table shows nothing more than can be explained on this basis, and no prognostic value can be placed upon the S.F. Reaction.

As to whether a negative reaction should be achieved by treatment before a patient can be considered cured, it is difficult to speak. During the study of normals it was seen that reactions up to 2 were found among persons apparently in perfect health. The influence of such diseases as yaws, syphilis, tuberculosis, etc., will certainly have to be considered, and not enough work has been done to show how the S.F.R. behaves during the treatment of these diseases. Syphilis, especially during the greater period of its course is most difficult to recognise among Africans, and in the absence of a laboratory sufficiently well equipped to perform the Wasserman test, it is impossible to say how many of the patients are suffering from this disease. The clinical condition has so far been the sole criterion for deciding whether a case should be placed on parole or not, and treatment has not been suspended in any patient where the S.F. Reaction was over 3.

It is suggested that in these cases where the S.F. Reaction will not fall any lower, though the patient appears cured, the existence of some intercurrent disease should be assumed and that a more thorough search with better facilities should reveal it.

\section{CONCLUSION.}

The following interpretation of the significance of these reactions has been evolved as a result of this investigation.

The Serum Formalin Reaction, when recorded as described, is of equal value with the Sedimentation Index in controlling the treatment of cases of leprosy. In dealing with the main disease itself it presents certain advantages over the Sedimentation Index in that it is influenced by few diseases, whereas the Sedimentation Index, not only changes with any illness, but is also influenced by the general fitness 
of the patient and by states of debility not amounting to actual disease. The comparison of the two reactions is of great assistance in determining whether any state of illhealth is attributable to an exacerbation of the specific disease or to some extraneous cause.

\section{SUMmaRY.}

1. The Botelho Reaction has been performed over a short series of cases. The proportion of positive results is too low for the reaction to be of value in the diagnosis of leprosy.

2. The Reaction of Rubino has been investigated under conditions that did not exactly correspond with those laid down by the originator of the technique. In these circumstances the test appeared useless for the early diagnosis of leprosy.

3. The Serum Formalin Reaction has been investigated over a series of patients suffering from leprosy and those not suffering, in the manner suggested by Dye, whereby the various intensities of the reaction can be numerically expressed. It was found to be high in such diseases as leprosy (especially of the nodular variety), tuberculosis, early syphilis, florid stages of yaws, trypanosomiasis and chronic bone sepsis. Positive reactions were found in a variety of other diseases, but never so high.

4. The Sedimentation Index has been recorded over the same series of cases. It appears to be a very delicate expression of debility.

5. In leprosy the Serum Formalin Reaction has been found to vary with the severity of the disease.

6. It has been found that simultaneous examination of the Serum Formalin Reaction and the Sedimentation Index in a case of leprosy is of value in the diagnosis of a leprous reaction and in its distinction from inter-current infections.

I have to express my thanks to Dr. A. H. Owen, the -Acting Director of Medical and Sanitary Services, Tanganyika, for permission to publish this paper, and Dr. R. R. Scott for valuable assistance in the final revision.

\section{REFERENCES.}

(1) Amies, C. R.-1929. "The Rubino Reaction in Leprosy." Bul. Inst. Med. Res., Federated Malay States, No. 4.

(2) Araujo, O. S.-1928. "Botelho's Reaction in Leprosy." Folha Med., Vol. ix, No. 10. 
(3) Baretto, F.-1926. "The Diagnostic Value of the Gate and Papacostos and Allied Reactions." Arquivos Indo-Portugueze de Med.e Historia Nat., Vol. 3.

(4) Dunscombe, W. K.-1927. "The Serum Formalin Reaction in Some Cases of Leprosy." Trans. Roy. Soc. Trop. Med. and Hyg. Vol. $\mathbf{x x}$, No. 8.

(5) Dye, W. H.-1926. "The Serum Formalin Reaction in Trypanosoma Rhodesiens Infection." Trans. Roy. Soc. Trop. Med. and Hyg., Vol. $\mathrm{xx}$, Nos. 1 and 2.

(6) Fox, E. C. R. and Mackie, F. P.-1921. "The Formol Gel Test in Kala Azar." Ind. Med. Gaz., Vol. lvi, No. 10.

(7) Iturbe, P. M.-1927. "The Rate of Sedimentation of Red Blood Corpuscles in Leprosy." Gac. Med. de Carcas, Vol. xxxiv, No. 1.

(8) Kerr, Isabel.-1929. "Notes on the Value of the Sedimentation Test in the Treatment of Leprosy." Ind. Med. Gaz., Vol. lxiv, No. 5.

(9) Labernadie, V., and Andre, Z.-1927. " Sedimentation of Red Cells in Leprosy." Bull. Soc. Path. Exot., Vol. xx, No. 9.

(10) Le Gac, P.-1930. "Botelho's Reaction in Leprosy." Bull. Soc. Path. Exot., Vol. xxiii, No. 1.

(11) Luz, A. C.-1929. "The Seriological Study of Leprosy." BrazilMedico., Vol. xliii, No. 50.

(12) Marchoux, E., and Caro, J.-1928. "A Serological Method of Diagnosis of Leprosy." Ann. Inst. Pasteur, Vo. xlii, No. 5.

(13) Molinelli, E. A.-1928. "Sedimentation of Erethrocytes in Leprosy." Semana Med., Vol. xxxv, No. 32.

(14) Monacelli, M.-1928. "Rubino's Reaction in Leprosy." Giorn. Ital. di Dermat. e Sifil., Vol. lxix, No. 5.

(15) Muir, E.-1928. "The Iodine Sedimentation Test in Leprosy." Ind. Journ. Med. Res., Vol. xvi, No. 1.

1929. "The Erythrocyte Sedimentation Test in Leprosy." Ind. Med. Gaz., Vol. lxiv, No. 9.

1930. "The Early Diagnosis of Leprosy." Leprosy Review, Vol. i, No. 4.

(16) Naiper, L. E.-1922. " A New Serum Test for Kala Azar." Ind. Journ. Med. Res, Vol. ix, No. 4.

(17) Paullier, Castro, V., and Errecart, L.-" Rubino's Leprosy Test." Rev. Med. Latino-Americana, Vol. xi.

(18) Peltier, M.-1928. "Value of Rubino's Method of Sedimentation in Leprosy." Bull. Soc. Path. Exot., Vol. xxi, No. 10.

(19) Puxeddu, E.-1924. "The Velocity of the Sedimentation of the Erythrocytes in Leprosy." Riforma. Med., Vol. iv, No. 22.

(20) Rogers, L., and Muir, E.-1925. " Leprosy." Bristol, John Wright and Sons.

(21) Rubino, M. C.-1926. "A New Serological Reaction in Leprosy." Rev. Hig. y Sanidad Pecuarias, Vol. xvi, No. 11.

1927. "Serological Reactions in Leprosy." C.R. Soc. Biol., Vol. lcvi, No. 3.

(22) Thomas, Marie.- "The Sedimentation of the Red Blood Cells in the Tropics." Geneesk, Tijdschr.v. Nederl-Indie, Vol.lxv, No. 2.

(23) Wade, H. W.-1925. "Preliminary Notes on Serological Findings in Leprosy, with special reference to certain Non-Specific Determinations." Far Eastern Assoc. Trop. Med. Trans. Sixth Biennial Congress Tokyo. Vol. ii. 